CrossMark

\title{
Strategic and experimental analyses of conflict and terrorism
}

\author{
Timothy Mathews ${ }^{1}$ (D) Shane Sanders ${ }^{2}$
}

Received: 29 October 2018 / Accepted: 30 October 2018 / Published online: 1 November 2018 (c) Springer Science+Business Media, LLC, part of Springer Nature 2018

\begin{abstract}
Understanding the root causes of conflict and terrorism ultimately will allow policymakers to enact measures to reduce violence's associated costs. This special issue on "Strategic and Experimental Approaches to the Study of Conflict and Terrorism" consists of papers that analyze issues related to conflict or terrorism using the tools of applied game theory or experimental economics. This introductory article provides an overview of, and explains the relationships between, the studies included in the special issue.
\end{abstract}

Keywords Conflict $\cdot$ Terrorism $\cdot$ Game theory $\cdot$ Experimental economics

JEL Classification D74 · C70 $\cdot$ H56 $\cdot$ F52

\section{Introduction}

Armed conflict and terrorism remain significant sources of human suffering and loss. Acquiring an understanding of their root causes will allow for a reduction in that toll. The analytical tools of applied game theory and experimental economics have been brought to bear on issues of conflict and terrorism for decades. The foundational tools of game theory formalized by von Neumann and Morgenstern (1944) were developed against the backdrop of the large-scale global military conflicts of the twentieth century; direct applications of game theory to the analysis of conflict date to Schelling (1960). Since then, analyzing issues of conflict using the tools of game theory has become standard practice. Such an approach accelerated following the work of Hirshleifer $(1983,1988)$. Still, academics have much to explore and contribute to knowledge in the relevant field of research.

The articles in this special issue on "Strategic and Experimental Approaches to the Study of Conflict and Terrorism" are a subset of papers presented in special sessions on

Timothy Mathews

tmmathews@gmail.com

Shane Sanders

sdsander@syr.edu

1 Department of Economics, Finance, and Quantitative Analysis, Kennesaw State University, Kennesaw, GA, USA

2 Department of Sport Management, Falk College of Sport and Human Dynamics, Syracuse University, Syracuse, NY, USA 
"Conflict and Security" that we organized at the 2017 International Conference on Game Theory at Stony Brook University. ${ }^{1}$ Several of the presenters at those sessions and contributors to this special issue participated previously in a "Workshop on Strategic Aspects of Terrorism, Security, and Espionage" at Stony Brook University in 2014. Thus, the 2017 conference afforded those scholars opportunities to continue the dialogue that first began at the 2014 workshop; the present special issue is intended to disseminate their findings to the broader academic community. ${ }^{2}$

The studies included in this special issue have a common focus on issues related to conflict or terrorism, employing the tools of applied game theory or experimental economics to inform their analyses. Because of the collective nature of resource-allocation decisions inherent in political and armed violence, the findings are of direct relevance and interest to public choice scholars and practitioners.

\section{Methodologies and findings of articles included in this special issue}

In the first contribution, Kovenock et al. (2018) study the allocations of defensive resources and choices of attack venues over a weakest-link network of targets, for which the aggressor has the objective of attacking successfully any one of the possible targets, while the defender has the objective of guarding all targets. Theoretical analyses of such an environment were provided earlier by Clark and Konrad (2007), under the assumption that the contest success function (CSF) at each target is a lottery CSF, and by Kovenock and Roberson (2017), who assumed that the contest success function at each target is an auction CSF. The present paper by Kovenock, Roberson and Sheremeta provides a complete characterization of the equilibrium in the lottery CSF version of the game and then provides an experimental test of the implications of both models. For the auction CSF game, experimental behavior aligns with theoretical equilibrium predictions, in that subjects assigned the role of attacker employ a stochastic "guerrilla-warfare" strategy of targeting a single site, while subjects assigned the role of defender employ a "complete coverage" strategy in which all sites are defended. In contrast, for the lottery CSF game, observed play is inconsistent with theoretical equilibrium predictions, in that attackers follow a "guerrilla-warfare" strategy instead of a "complete coverage" strategy. Finally, consistent with theoretical predictions, under both CSF forms, as the attacker's target valuation increases, the attacker chooses to expend more resources and the defender chooses to expend fewer resources. Such behavior raises the probability of a successful outcome and increases the expected payoff for the attacker (and lowers the probability of a successful outcome and reduces the expected payoff for the defender).

The next article, by Aycinena et al. (2018), also utilizes an experimental methodology to study issues related to conflict. More precisely, building on the theoretical work of Baye et al. (1996), Krishna and Morgan (1997) and Siegel (2014), the authors study the behavior of participants in an all-pay auction environment with incomplete information under differing assumptions on target valuation structures. Potential applications to diverse contexts ranging from sporting contests, to lobbying, to warfare are noted. Experiments are

\footnotetext{
1 We are grateful to Conference organizers John Geanakoplos, Ehud Kalai and Abraham Neyman for including the sessions as part of the larger event.

${ }^{2}$ We are equally grateful to Public Choice Editor-in-Chief William Shughart for devoting scarce journal space to this special issue.
} 
conducted for three distinct valuation structures: pure common-value; pure private-value; and mixed environment, in which valuations have both a common and a private component (the case that likely best describes most real-world contest environments). The experimental results reveal that across all information structures it is quite common for some subjects to expend resources well below theoretical predictions, while others expend resources well above theoretical predictions. Average resource expenditures exceed equilibrium predictions, leading participants to earn, on average, negative payoffs. Most surprisingly, in treatments for which the valuation structure has a common value component, subjects regularly choose expenditures above the expected value of the prize conditional upon winning, behavior that in an all-pay environment guarantees a negative payoff in expectation (and an extremely large loss if the contest is not won). The practical implications for the significant social costs of rent seeking in such an environment are apparent.

In the next study, Chang and Sellak (2018) explore the impact of international trade on conflicts between nation-states over territories rich in natural resources. They do so by developing a game theory-based model of international trade in which natural resource appropriation by an aggressor is possible. The seminal work of Polachek (1980) establishes the empirical motivation for the inquiry, while Skaperdas and Syropoulos (2001) provide the theoretical foundation. Consistent with the "liberal peace hypothesis", Cheng and Sellek find that greater trade openness (i.e., reduced trade costs/barriers) leads to lower levels of pre-conflict arming by symmetric adversaries. Using those results as a benchmark, an asymmetric environment in which adversaries have different natural resource endowments is considered. The identified equilibrium in this asymmetric case is characterized by the country with the greater natural resource endowment arming more heavily. A comparative statics analysis reveals that the two states respond differently to changes in the extent of trade openness. As trade costs are lowered, the country with the greater natural resource endowment will reduce its level of arming while the country with the lesser natural resource endowment might raise, lower, or not change its level of arming. Moreover, the combined arming allocations of the two adversaries could either increase, decrease, or remain unchanged as trade costs decline.

Bagchi et al. (2018) examine conflicts between nation-states further, in particular, socalled proxy wars. The question of why countries sometimes use proxy agents instead of engaging in conflict directly has been considered previously by Salehyan (2010) and Salehyan et al. (2011). With the war in Syria and the ascendance of ISIS as motivation, the article develops and analyzes a model of a proxy war between three combatants, each with a distinct sponsor who provides resources that serve as direct complements to the recipient combatant's own effort in the actual conflict. This six-player game is a dynamic contest, a type of environment studied earlier by Konrad (2012). The setup is asymmetric in that two of the sponsors have partially aligned interests with a strong aversion to the third sponsor (but not to each other). Restricting attention to pure strategy equilibria, three different outcomes are possible (depending on the model's parameters). If the ex-post value of winning the contest is small, then all combatants end up actively participating in the conflict. On the other hand, if the ex-post value of winning the contest is large, then only two combatants actively will fight - either the clients of the two sponsors with partially aligned interests fight each other or one with a partially aligned sponsor fights against the combatant supported by the third sponsor. Finally, incentives for and conditions under which the sponsors with partially aligned interests would choose to form an alliance are identified.

Boudreau et al. (2018b) consider the influence of noise in conflicts involving the related elements of alliance formation and collusion. When noise is modeled as an exponential parameter in the contest success function (see, e.g., Nti 1999), the study finds that alliance 
formation can raise the expected payoffs to allied parties above those received in the case of no alliance. That is to say, the alliance formation puzzle (see, e.g., Konrad 2009) is solved in the case of sufficiently noisy contests. In such circumstances, allocative noise mitigates reductions in the equilibrium probability of success for the allied party (stemming from free riding). For such contests, the cost savings from free riding outweigh the decline in the probability of victory for allied parties, and players are better off if they form an alliance. It is perhaps the case, then, that the empirical observation of alliance formation can be explained by the presence of sufficient allocative noise among a class of real-world conflicts.

Boudreau et al. (2018a) analyze a three-party conflict setting in which the potential for alliance formation exists. In their study, the authors consider a novel ("stag hunt") alliance technology within the (Tullock-style) contest success function, one that accounts for potential complementarities between allied parties. Previous contributions to alliance formation in conflict (see, e.g., Konrad 2009; Konrad and Kovenock 2009; Ke et al. 2013) consider only alliances that contribute conflict inputs that serve as substitutes for one another. In such a conflict alliance, a collective action problem drives down alliance arming and also expected (aggregate) alliance payoff. Unlike the case presented in the traditional contest alliance setting, Boudreau et al. (2018a) find that (a) allied party allocations can be solved for uniquely in the case of stag hunt alliances and (b) conditions exist under which the complementarity effect of a stag hunt alliance can overcome the collective action problem, such that expected allied party payoffs increase (compared to the case of no alliance).

Mathews et al. (2018) consider a model of attacker-defender interaction. The model presents a one-shot, Stackelberg game in which an attacker (terrorist) party may target a state party. In the first stage of the game, the state party chooses its defensive resource allocation. In the second stage, the potential attacker chooses whether or not to attack. The game departs from a traditional conflict model (see, e.g., Hirshleifer 1989 or, for a traditional Stackelberg treatment, e.g., Chang et al. 2007 or Chang and Sanders 2009) in that the terrorist's payoff from a successful attack increases in the degree to which the state party fortifies its target. The authors reason that the level of fear generated by a successful attack increases when a target is well-fortified. Additionally, success allows the terrorist organization to recruit more effectively. In equilibrium, the authors find that such a terror effect raises the cost to the state of deterring attacks successfully, so that no attack is undertaken. The paper obviously has important implications for defending against and averting terrorist attacks.

Jiao and Luo (2018) consider a model in which terrorists and state parties engage in a conflict game that features location choices. In its consideration of location choice by a terrorist party, the study is closely related to issues examined previously by Bier et al. (2007) and Mathews and Lowenberg (2012). In the model, three geographically differentiated target locations are assumed where the last location is known only by the terrorist party. Location choice and defensive resource allocation for the state party are found to depend on whether the first two locations are attacked simultaneously or sequentially. The paper's results generalize to other contest and conflict settings. As in Mathews et al. (2018), the (sequential or simultaneous) structure of the game influences the outcomes of conflicts between a terrorist group and a state actor. 


\section{Concluding observations}

Clearly understanding the fundamental causes of conflict and terrorism will allow policymakers to enact measures to mitigate their negative impacts. Owing to the collective nature of resource allocation decisions inherent in such contests, their relevance and interest to public choice scholars and practitioners is apparent. While the tools of applied game theory and experimental economics have been bought to bear in analyzing such issues for decades, scholars still have much to learn. The papers in this special issue continue that important inquiry, furthering our understanding of the complex issues raised by terrorism and efforts to counter it.

\section{References}

Aycinena, D., Baltaduonis, R., \& Rentschler, L. (2018). Valuation structure in incomplete information contests: Experimental evidence. Public Choice. https://doi.org/10.1007/s11127-018-0568-7.

Bagchi, A., Faria, J. R., \& Mathews, T. (2018). A model of a multilateral proxy war with spillovers. Public Choice. https://doi.org/10.1007/s11127-018-0586-5.

Baye, M., Kovenock, D., \& de Vries, C. (1996). The all-pay auction with complete information. Economic Theory, 8(2), 291-305.

Bier, V., Oliveros, S., \& Samuelson, L. (2007). Choosing what to protect: Strategic defensive allocation against an unknown attacker. Journal of Public Economic Theory, 9, 563-587.

Boudreau, J. W., Rentschler, L., \& Sanders, S. (2018a). Stag hunt contests and alliance formation. Public Choice. https://doi.org/10.1007/s11127-018-0567-8.

Boudreau, J. W., Sanders, S., \& Shunda, N. (2018b). The role of noise in alliance formation and collusion in conflicts. Public Choice. https://doi.org/10.1007/s11127-018-0564-y.

Chang, Y. M., Potter, J., \& Sanders, S. (2007). War and peace: Third-party intervention in conflict. European Journal of Political Economy, 23(4), 954-974.

Chang, Y. M., \& Sanders, S. (2009). Raising the cost of rebellion: The role of third-party intervention in intrastate conflict. Defence and Peace Economics, 20(3), 149-169.

Chang, Y. M., \& Sellak, M. (2018). A game-theoretic analysis of international trade and political conflict over external territories. Public Choice. https://doi.org/10.1007/s11127-018-0505-9.

Clark, D. J., \& Konrad, K. A. (2007). Asymmetric conflict: Weakest link against best shot. Journal of Conflict Resolution, 51, 457-469.

Hirshleifer, J. (1983). From weakest link to best shot: The voluntary provision of public goods. Public Choice, 41, 371-386.

Hirshleifer, J. (1988). The analytics of continuing conflict. Synthese, 76, 201-233.

Hirshleifer, J. (1989). Conflict and rent-seeking success functions: Ratio vs. difference models of relative success. Public Choice, 63(2), 101-112.

Jiao, Y., \& Luo, Z. (2018). A model of terrorism and counterterrorism with location choices. Public Choice. https://doi.org/10.1007/s11127-018-0559-8.

Ke, C., Konrad, K. A., \& Morath, F. (2013). Brothers in arms-an experiment on the alliance puzzle. Games and Economic Behavior, 77(1), 61-76.

Konrad, K. A. (2009). Strategy and dynamics in contests. New York, NY: Oxford University Press.

Konrad, K. A. (2012). Dynamic contests and the discouragement effect. Revue d'Economie Politique, $122,233-256$.

Konrad, K. A., \& Kovenock, D. (2009). The alliance formation puzzle and capacity constraints. Economics Letters, 103(2), 84-86.

Kovenock, D., \& Roberson, B. (2017). The optimal defense of networks of targets. Chapman University, Economic Science Institute, working paper no. 17-18.

Kovenock, D., Roberson, B., \& Sheremeta, R. (2018). The attack and defense of weakest-link networks. Public Choice. https://doi.org/10.1007/s11127-018-0618-1.

Krishna, V., \& Morgan, J. (1997). An analysis of the war of attrition and the all-pay auction. Journal of Economic Theory, 72(2), 343-362. 
Mathews, T., Bagchi, A., \& Faria, J. R. (2018). Simple analytics of the impact of terror generation on attacker-defender interactions. Public Choice. https://doi.org/10.1007/s11127-018-0538-0.

Mathews, T., \& Lowenberg, A. D. (2012). The interdependence between homeland security efforts of a state and a terrorist's choice of attack. Conflict Management and Peace Science, 29(2), 195-218.

Nti, K. O. (1999). Rent-seeking with asymmetric valuations. Public Choice, 98(3-4), 415-430.

Polachek, S. M. (1980). Conflict and trade. Journal of Conflict Resolution, 24, 55-78.

Salehyan, I. (2010). The delegation of war to rebel organizations. Journal of Conflict Resolution, 54(3), 493-515.

Salehyan, I., Gleditsch, K. S., \& Cunningham, D. E. (2011). Explaining external support for insurgent groups. International Organization, 65, 709-744.

Schelling, T. C. (1960). The strategy of conflict. Cambridge, MA: Harvard University Press.

Siegel, R. (2014). Asymmetric all-pay auctions with interdependent valuations. Journal of Economic Theory, $153,684-702$.

Skaperdas, S., \& Syropoulos, C. (2001). Guns, butter, and openness: On the relationship between security and trade. American Economic Review, Papers and Proceedings, 91, 353-357.

von Neumann, J., \& Morgenstern, O. (1944). Theory of games and economic behavior. Princeton, NJ: Princeton University Press. 